eeISSN: 2387-1555

DOI: http://dx.doi.org/10.14201/rea202096173

\title{
MEMORIAS DE LUGARES E HISTORIAS DE REGIONES ENTRE LOS PIMAS. ${ }^{1}$ \\ Memories of places and Histories of Regions Among the Pima \\ Memórias de lugares e Histórias de Regiões entre os Pima
}

\author{
Margarita HOPE \\ Escuela de Antropología e Historia del Norte de México. \\ Instituto Nacional de Antropología e Historia. \\ $\triangle$ margarita_hope@inah.gob.mx \\ ORCID: https:/ / orcid.org/0000-0001-9560-7830
}

Fecha de recepción: 10 de junio de 2019

Fecha de aceptación: 13 de diciembre de 2019

\begin{abstract}
Resumen: En este trabajo propongo contrastar las nociones sobre el pasado asociadas a los ámbitos de la vida de los pimas; aquellas que corresponden a las narrativas de los propios actores sociales y las que se desprenden de la mirada del analista. Revisaré, por un lado, las regiones históricas denominadas Pimerías que constituyen un primer ejercicio de delimitación cultural del noroeste de México. Se trata de áreas identificadas a partir de registros y documentos que fijaron lo dicho por los misioneros y colonizadores de finales del siglo XVI y principios del siglo XVII. Por otro lado, me aproximaré a los lugares en los que habitan los pimas, los que ellos trazan con sus prácticas cotidianas y señalan en sus procesos rituales; donde establecen la continuidad en el tiempo y en el espacio con quienes les antecedieron y con quienes les seguirán. Los pimas contemporáneos han tomado las riendas de su cultura, se distancian de aquellos con quienes otros los han unido en regiones trazadas desde la Historia, para acercarse a quienes participan con ellos en el diseño de un futuro enraizado en su memoria.
\end{abstract}

Palabras claves: memorias; historias; regiones; lugares; pimas.

\begin{abstract}
In this paper, I propose to contrast the notions about the past related to the world of the Pima; those that correspond to the narratives of the social actors themselves and those that emerge from the analyst's gaze. I will review, on the one hand, the historical regions called Pimerías that constitute a first exercise of cultural delimitation on northwestern Mexico. These are areas identified from records and documents that established whatwas said by the missionaries and colonizers of the late sixteenth and early seventeenth centuries. On the other hand, I will approach the places where the Pimas live, which they trace with their daily practices and point out in their ritual processes, where they establish continuity in time and space with those who preceded them and with those who will follow them. Contemporary Pimas have taken the reins of their culture; they distance themselves from those with whom others have united them in regions traced from history, to approach those who participate with them in the design of a future rooted in their memory.
\end{abstract}

Keywords: memories; stories; regions; places; pimas.

Resumo: Neste artigo proponho contrastar as noções sobre o passado associadas às esferas da vida dos Pimas; aquelas que correspondem às narrativas dos próprios atores sociais e outras que emergem do olhar do analista. Vou rever, por um lado, as regiões históricas chamadas Pimerías que constituem um primeiro exercício de delimitação cultural do noroeste do México. Estas são áreas identificadas a partir de registros e documentos que estabeleceram o que foi dito pelos missionários e colonizadores do final do século XVI e início do século XVII. Por outro lado, abordarei os lugares onde vivem os Pimas, o que eles traçam com suas práticas diárias e assinalam em seus processos rituais; onde eles estabelecem continuidade no tempo e espaço com aqueles que os precederam e com aqueles que os seguirão. Os Pimas contemporâneos tomaram as rédeas de sua cultura; eles se distanciam daqueles com quem outros os teriam unidos em regiões traçadas da na história, para aproximar-se daqueles que participam com eles no projeto de um futuro enraizado em sua memóri

Palavras-chave: memórias; histórias; regiões; lugar; pimas.

${ }^{1}$ Este artículo se desprende de la tesis doctoral Las Pimerías. Hacia un campo de estudio etnológico en el noroeste de México, que se defendió en 2016 en la Universidad de Salamanca, España. Por otro lado, el texto incorpora reflexiones desprendidas del Seminario de la línea de investigación "Etnografía e Historia del Norte de México" de la Maestría en Antropología Social, de la Escuela de Antropología e Historia del Norte de México; así como del Programa Nacional de Etnografía de las Regiones Indígenas de México, del Instituto Nacional de Antropología e Historia. 


\section{Presentación}

Los pimas son un pueblo originario del noroeste de México, sus principales asentamientos se encuentran en la franja fronteriza entre los estados de Sonora y Chihuahua en las inmediaciones de la Sierra Madre Occidental. Estos pimas tienen como etnómino los términos O’ob del lado de Sonora y O’oba del lado de Chihuahua. También hay importantes asentamientos pimas en el suroeste de Estados Unidos de Norteamérica en la región desértica del estado de Arizona; los Akimel O’otham (gente del río) son los pimas establecidos en las riberas del río Gila y del río Salado. La región que habitan los pimas en territorio mexicano se encuentra dentro de lo que históricamente se conoció como Baja Pimería, mientras que los pimas de Arizona tienen sus hogares dentro de los límites de lo que una vez se conoció como Pimería Alta.

La clasificación de Alta y Baja Pimería, responde a una delimitación geográfica, espacial, no en el sentido de la altitud sino de la latitud que correspondía a ladirección en que iban avanzando los colonizadores y misioneros españoles. Son categorías históricas para hablar de las regiones que jugaron un papel central en la definición de la frontera norte de la Nueva España. Sus habitantes representaban un conjunto de diversos grupos que fueron configurándose y reconfigurándose en función de sus relaciones tanto con los colonizadores como con los otros grupos de los que eran vecinos.

En la actualidad, los pimas son un grupo aparentemente «aculturado», muchos antropólogos han vaticinado su desaparición desde hace ya casi un siglo, el propio Lumholtz no era muy optimista sobre las posibilidades de continuidad cultural de este pueblo indígena de la Sierra Madre Occidental. Sin embargo, pese a su falta de atractivo para los ojos de los etnógrafos que les han dedicado poca tinta - hace apenas un par de décadas que los antropólogos mexicanos se han dado a la tarea de escribir sobre ellos- y a la preocupación de los lingüistas que insisten en señalar el riesgo de la pérdida de su lengua, los pimas siguen siendo lo que ellos creen que siempre han sido.

En 1992, Marshall Sahlinsproponía el desarrollo de una etnografía histórica que, a partir de un análisis retrospectivo, permitirá entender las transformaciones estructurales de una cultura especialmente cuando ésta parecía haberse diluido. De acuerdo con esta propuesta, en el caso de los pimas, ante una etnografía escasa podemos recurrir a la Historia de las regiones delimitadas desde las crónicas coloniales en las que se configura la «Pimería» para vincularla con la memoria de los lugares en los que habitan hoy, de manera que podamos dar cuenta de los cambios de la cultura pima y su reinvención constante en donde la memoria es el recurso para transformar, como diría Sahlins, «la modernidad global en diversidad local» (1993:1).

\section{Historias de regiones: Las Pimerías}

Me aproximo a la historia y etnografía de las Pimerías a partir de los trabajos que condensan la información sobre cómo se constituyeron éstas como dos regiones culturales distintas tanto para su conquista y evangelización como para su estudio.Con la revisión de las delimitaciones que dieron lugar a la construcción histórica de estas regiones no pretendo identificar sus límites ni fijar sus fronteras geográficas exactas. La intención es dar cuenta de la forma en que se establecieron continuidades y discontinuidades bajo los criterios de quienes llegaron a ocupar los territorios en los que habitaban distintos grupos que se vieron transformados a partir del trazo de nuevas fronteras. En este sentido, estamos de acuerdo con Alfredo Jiménez Núñez cuando señala que: 
"La frontera, en cuanto situación extraña y extrema, lleva a las sociedades en contacto a utilizar y hacer explícitos recursos y contenidos que, de otra forma, serían difíciles de conocer. Ocurre en los espacios de frontera lo que con terminología actual y corriente denominamos 'situaciones de emergencia'. Las fronteras son, inevitablemente, causa de cambio culturals (2003:102-103).

Es justamente ese «cambio cultural» provocado por el establecimiento de los límites fronterizos del norte de la Nueva España (que estuvo acompañado de demarcaciones regionales como las de Alta y la Baja Pimería)el que abordo en este trabajo con el objetivo de identificar la tensión entre la historia de una región que impactó en la configuración cultural de su población y la memoria de sus habitantes contemporáneos que trazan continuidades culturales sobre las discontinuidades geográficas.

Lo primero que hay que señalares el hecho de que el origen de las denominaciones de Alta y Baja Pimería se ubica en el proceso de conquista y colonización española que alcanzó estos territorios en el siglo XVII. La necesidad de clasificar a los grupos sobre los que se iban a imponer, llevó a encontrar comunes denominadores a partir de los cuales se unificaron en extensos conglomerados. El mismo proceso de avanzada, colonización y evangelización del septentrión mexicano provocó la reconfiguración de sus habitantes de manera que los límites étnicos se alteraron.

Carl Sauer, en la introducción a su artículo sobre «La distribución de las tribus y las lenguas aborígenes del Noroeste de México» lo describe así:

\begin{abstract}
«La llegada de los españoles provocó en todas partes el desplazamiento de los nativos, si no de manera violenta en todos los casos, sí en cambio de forma efectiva [...] Los reales de minas pronto contribuyeron a la disminución de los indios en las áreas colindantes, al igual que a la deforestación de los bosques. Asimismo, de gran importancia fueron los traslados de indios que efectuaron las misiones, es decir, las llamadas "reducciones". A hí las tribus más débiles fueron absorbidas por las fuertes, y no pocas fueron desapareciendo en el proceso de mexicanización, es decir, el paso de 'indio' a 'gente de razón', primero mediante la mezcla de las etnias indigenas para anular la conciencia tribal, más tarde por mestizaje [...] La encomienda pronto representó el fin de la individualidad tribal (1998 [1934]:9798)».
\end{abstract}

A partir de esto podemos entender cómo la enorme diversidad con la que se iban encontrando los colonizadores en su expansión hacia el norte de la Nueva España, representaba un escenario complejo que tenía que ser simplificado para su conquista. De tal suerte que se crearon grandes categorías para clasificar a distintos grupos tribales que tuvieran algún común denominador, por ejemplo, la lengua. De la misma manera, se establecieron límites regionales a partir de los cambios en la geografía y la ecología que permitieran trazar estrategias distintas en contextos diversos. Así van a surgir como categorías clasificatorias de la diversidad ecológica y geográfica las denominaciones de Alta y Baja Pimerías; que suponían algún nivel de unidad lingüística y tal vez cultural en su interior.

Existe una asimetría importante entre las dos Pimerías en términos de su estudio y de la información que sobre ellas se tiene. Mientras que la Pimería Alta representa una de las regiones mejor documentadas y, por lo tanto, más estudiadas en términos históricos; la Pimería Baja no cuenta con el mismo arsenal de documentos y archivos que permita un trabajo historiográfico semejante al que se ha realizado sobre la Alta. Sin embargo, existen trabajos como el de Carl Sauer y Luis González R. que nos arrojan luz sobre ella. En uno de los relatos del jesuita Luis Xavier Velarde (1716), reproducido por Luis González, explica que el origen del término pima para referirse a los habitantes de esta zona del noroeste de México se encuentra en la expresión de negación «pim» que solían repetir los «ootoma» y «otama» en singular, que es como se llamaban así mismo los pobladores de este lugar (VELARDE, apud GONZÁLEZ, 1977:27). 


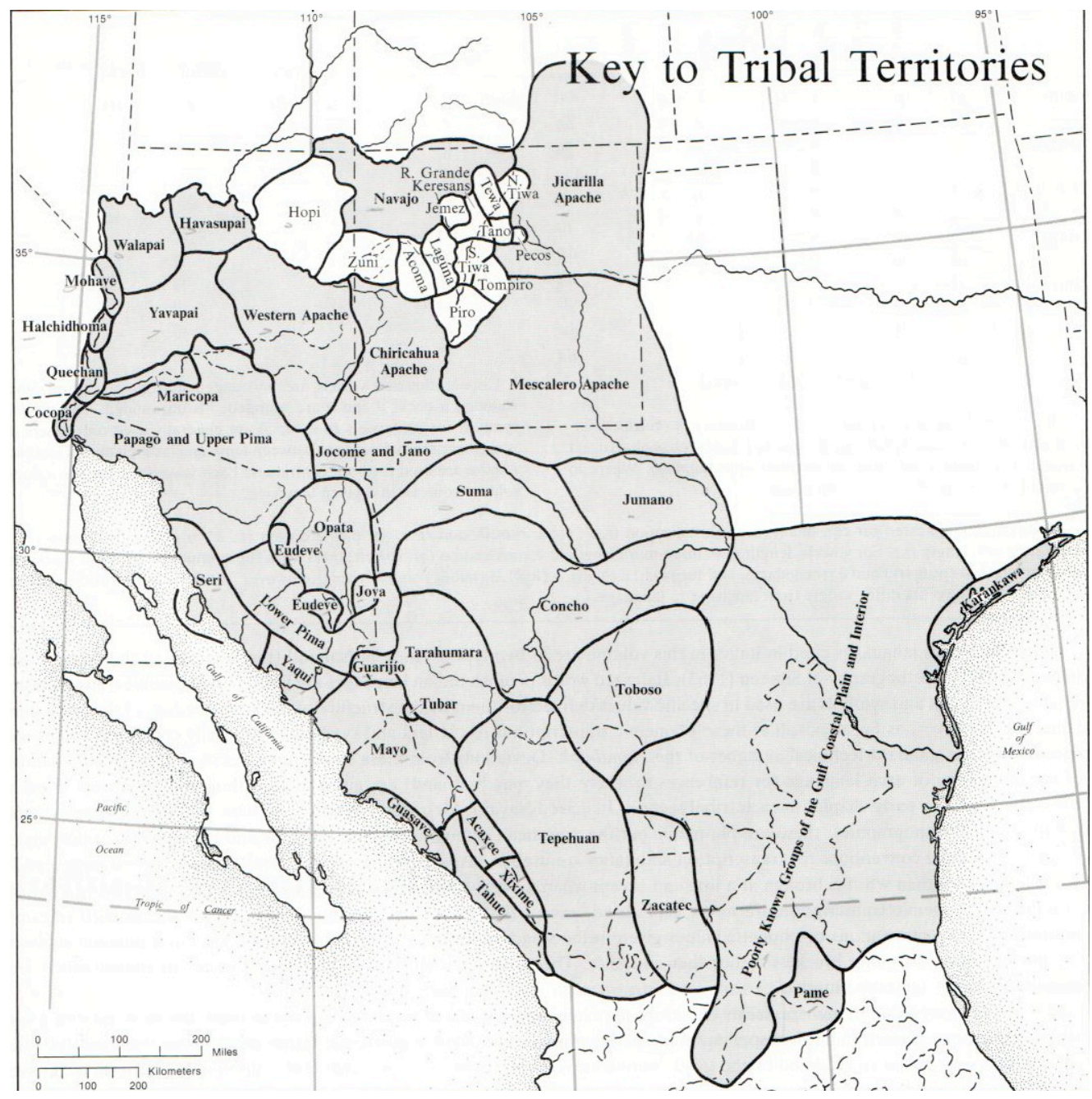

Figura $n^{\circ}$ 1. Distribución de los grupos indígenas que desde antes de la colonización europea ocuparon el extenso territorio que comprende el suroeste de Estados Unidos y el noroeste de México. Fuente (Ortiz, 1983).

De esta manera, podemos pensar que los pimas eran quienes decían «pim» y las Pimerías se definieron por la continuidad de habitantes que utilizaban esta negación.

En la relación elaborada por este misionero, podemos encontrar una serie de datos que nos permiten observar que estas vastísimas regiones eran en realidad espacios de diversidad; en su interior habitaban una variedad de grupos que compartían una lengua con variantes dialectales o, en el caso de lenguas distintas, la pertenencia al mismo tronco lingüístico. Fue a partir de esto que se estableció la continuidad regional a pesar de que hubiera variaciones geográficas tan considerables. La relación de «naciones» que habitan en la denominada Pimería Alta muestra una gran diversidad de grupos emparentados a los que los cronistas (misioneros y/o conquistadores) dieron el mismo nombre de pila. Así tenemos a grupos como: pimas sobas, pimas sabaipuris y pimas pápagos (VELARDE apud GONZÁLEZ, 1977).

A pesar de la delimitación tan puntual que se hizo de los lindes de la Pimería Alta y de que existen documentos que identificaron con mucha precisión prácticamente todos los asentamientos pimas, Sauer advierte que los límites de esta región hacia el noreste no tienen una frontera clara. 


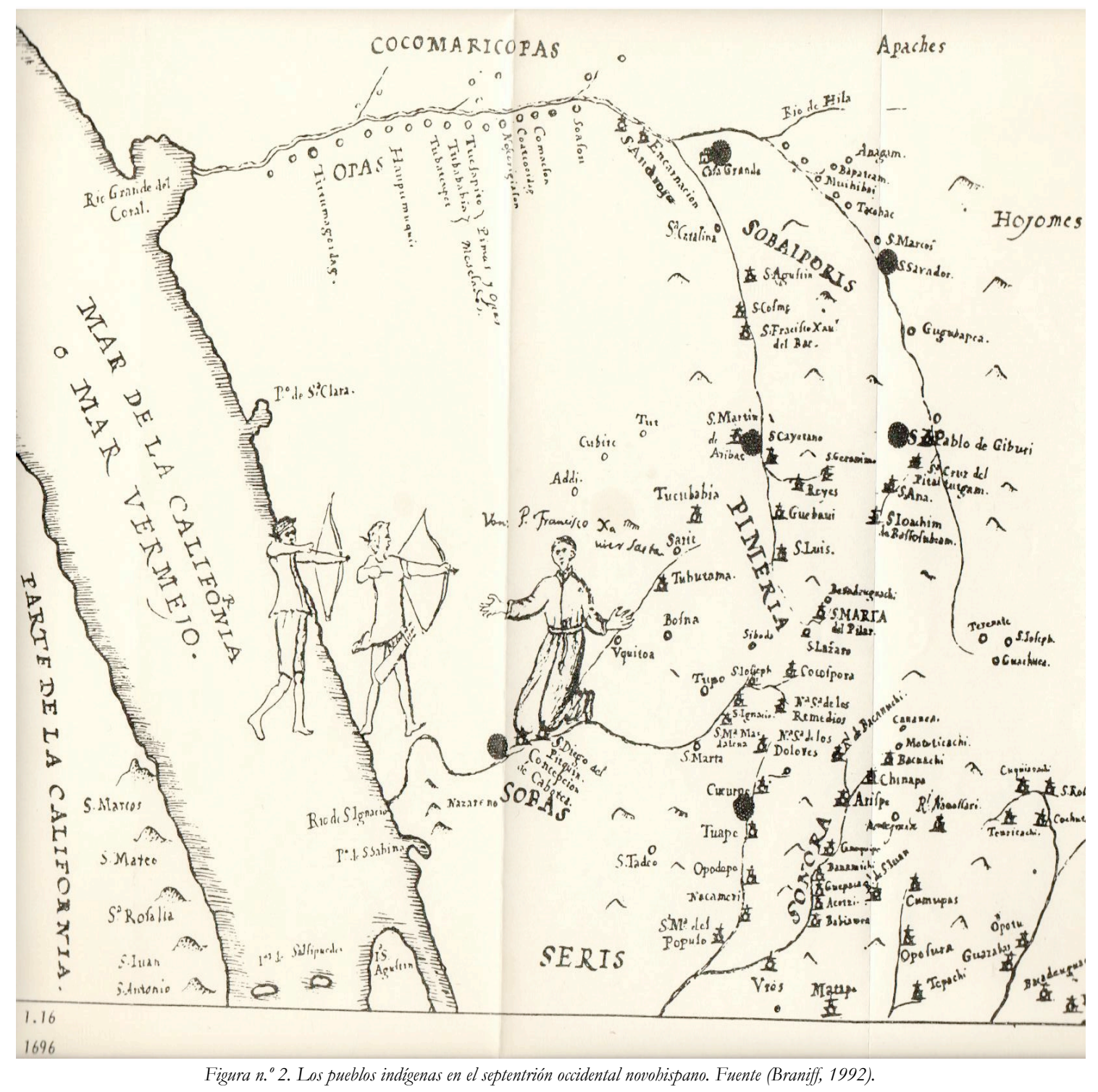

Y señala que al norte de lo que se conoce como «El valle Salado» en el alto Gila, habitaban los apaches, enemigos de los pimas. En la crónica de Vázquez de Coronado se refiere a ellos como «las gentes más bárbaras que jamás se hayan visto. Viven en chozas separadas y no en poblados; viven de la cacería» (apud SAUER,1998 [1934]:157).

La figura de los apaches representa la alteridad frente a los pimas - en general frente a los grupos que habían sido organizados a partir de las misiones- y serán un referente simbólico e identitario central en el discurso de los pimas sobre sí mismos. En diferentes ocasiones, incluso en algunos rituales, la figura de los apaches va a representar la adversidad que han tenido que superar los pimas tanto de la Alta como de Baja. Los vecinos más cercanos de los apaches, los pimas más septentrionales, será los denominados sobaipuris que ocupaban el valle del río San Pedro en el actual estado de Arizona, al norte del Gila. Sauer nos dice que este mismo nombre se daba a los pimas que habitaban el área de Tucson (1998 [1934]:158), por lo que podemos pensar que se trata de los que antecedieron a los Akimel O'otham² que ocupan esa región en la actualidad

2 O’otham se refiere a «gente» en las lenguas tepimanas; también se acepta la grafía O’odam. Akimel O’otham (gente del río) y Tohon O'otham (gente del desierto), son los habitantes contemporáneos de lo que históricamente se denominó Pimería Alta. 
De acuerdo con las investigaciones de la arqueóloga mexicana Beatriz Braniff (1992), uno de los principales criterios en la definición de regiones en el noroeste de México sería el ecológico; pues a partir de éste se pueden trazar diferentes tradiciones culturales asociadas con las particularidades del medio en el que habitan. De esta manera, en su trabajo «La Frontera protohistórica pima-ópata en Sonora, México», Braniff va a identificar al Río San Miguel como una frontera ecológica y etnohistórica que demarca hacia el occidente la región del desierto y hacia el oriente la región serrana. Este río separaba, en términos etnohistóricos, a la Pimería Alta ubicada en el occidente, de la Opatería que se desarrollaba hacía el oriente de este afluente (1992:19-24). En este sentido, para Braniff, la distinción más relevante sería aquella que se marca entre los grupos que habitan en el desierto frente a los de la sierra o las regiones más propicias para el cultivo.

Después de la revisión de estos autores, está claro que la Pimería Alta se refiere a la región occidental respecto del río San Miguel, la parte septentrional desértica del estado de Sonora que corre hasta internarse en el estado de Arizona y que encuentra sus límites entre los cauces del norte de río Gila y hacía el oriente el río San Pedro. Pero ¿quiénes son entonces los pimas altos si no son los pápagos, los sobas o los sobaipuris. Los pimas altos son todos esos grupos que habitan la Pimería Alta, por lo tanto, a los que los autores y los cronistas se refieren simplemente como pimas serían aquellos grupos que se quedan sin una clasificación particular, sin una ubicación específica en ese vasto desierto.

Lo que resulta particularmente interesante, a partir de todas estas apreciaciones, es el hecho de que por un lado hubo grupos que se fueron fundiendo y, en algunos casos, perdiendo entre otros hasta convertirse en algún tipo de «indio» genérico (como lo advertía antes Sauer). Pero también se dio el proceso contrario, grupos como los pápagos que en principio eran considerados o aparecían en las crónicas como un tipo específico de pimas y fueron cobrando una relevancia tal en la región que terminaron «particularizándose», si se me permite la expresión, hasta un punto en que terminaron por ser considerados como «otros» indios. Incluso se ha llegado a plantear que los pimas altos de territorio mexicano se terminaron por diluir entre los pápagos (Tohon o'otham).

De hecho, en la actualidad, los pápagos son el único pueblo indígena que habita en la región que correspondería a la porción mexicana de la Pimería Alta. Desde el discurso etnológico contemporáneo son un grupo claramente diferenciado de los pimas. Se dice que comparten entre ellos la misma familia lingüística pero no la misma lengua. Los procesos históricos y los discursos etnicistas los han llevado a presentarse como grupos distintos; con una historia compartida, pero con una memoria que los lleva a trazar diferentes proyectos étnicos.

En la Pimería Alta del lado estadounidense encontramos ahora asentados, además de a los pápagos (que son un grupo binacional), a los pimas de la reservación del Río Gila (Akimel O’otham) y también de la reservación de Salt River que comparten con los Maricopa (Pee-Posh). También en esta región, a raíz de los movimientos migratorios, habitan grupos de indígenas yaquis.

Los únicos grupos que se identifican como pimas en territorio mexicano son los que habitan en los poblados del municipio de Yécora en Sonora (Maycoba, La Dura, El Kipor, El Encinal, Los Pilares y una colonia dentro de la cabecera municipal de Yécora llamada San Diego de los pimas); en algunas localidades del municipio de Temósachic (Yepachi, Piedras Azules, La Guajolota, Nabogame, San Antonio) y del municipio de Madera en Chihuahua (Los Ojitos, Tierra Blanca, Agua Amarilla, el Garabato, El Cable). Este último municipio no estaba contemplado dentro de los límites que definían a la Pimería Baja, aunque sí se podría ubicar dentro de los lindes de la Opatería. 
La presencia de los pimas en la actualidad se atribuye a un proceso de migración desde Yepachi, sin embargo, encontramos un discurso entre los pimas del municipio de Madera que reivindica el hecho de que ellos han habitado esos territorios desde siempre, que también son descendientes de los apaches.

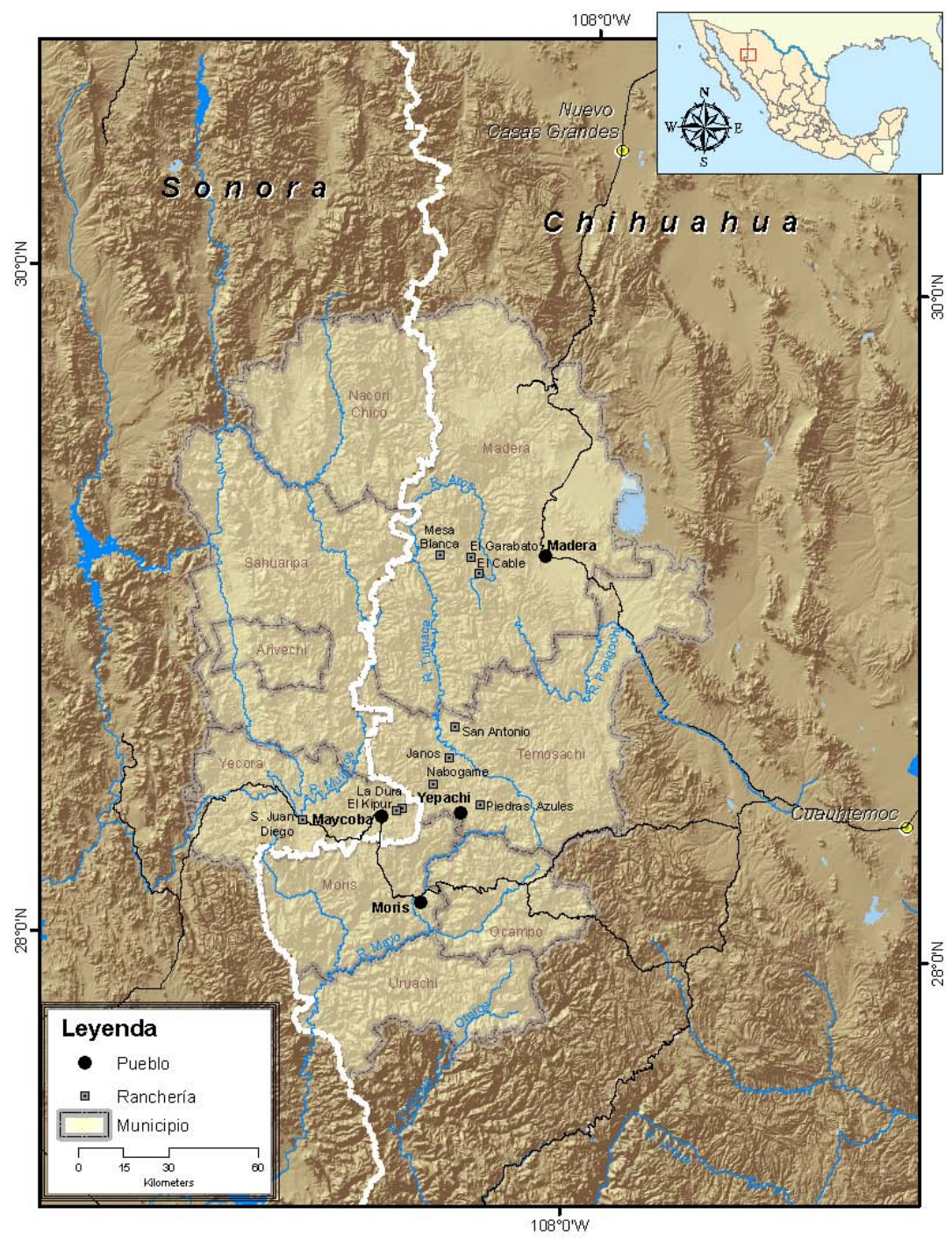

Figura n. ${ }^{\circ}$. Ubicación actual de los pueblos y rancherías pimas en Chibuabua y Sonora. Elaborado por Enrique Chacón en 2011. Fuente (Oseguera, 2013).

En nuestros días, las denominaciones en función de las Pimerías Alta y Baja parecen haber caído en desuso y se piensan más como un referente histórico que etnológico. Solemos encontrar con mayor frecuencia referencias en términos de pimas del desierto o pimas de la sierra; que equivaldría a los pimas de Arizona y los pimas de Chihuahua y Sonora. En la antropología mexicana contemporánea cuando se dice pimas se piensa en los serranos, en los llamados o'ob u o'oba que ocupan los territorios que corresponderían a la llamada Pimería Baja. En contraste con la Pimería Alta, como lo advertimos en el apartado anterior, la Pimería Baja es una región mucho menos documentada, menos estudiada y, por lo tanto, menos conocida en términos históricos e incluso lingüísticos. Sin embargo, dentro de sus límites se encuentran los lugares en los que he realizado trabajo de campo y de investigación etnográfica en los últimos años; por lo tanto, es una región con la que estoy más familiarizada.

En el intento que hace Carl Sauer por reconstruir el panorama étnico con el que se encontraron los colonizadores y misioneros españoles al avanzar por el noroeste de México durante el siglo XVII, va a 
identificar a los pimas bajos como el grupo nébomesque vivía en las riberas del río Yaqui. Reconoce que los pimas bajos eran llamados también sobiapapus, particularmente los que vivían al lado del río Suaqui Grande (SAUER, 1998 [1934]). A pesar de que en esta región hubo una fuerte presencia de misiones jesuitas desde 1619, la mayoría de la información producida por ellos se perdió. Sin embargo, el proceso de evangelización fue muy exitoso de acuerdo al recuento que hace Sauer a partir de datos fragmentados con los que se fue encontrando.

En las fuentes producidas por la Compañía de Jesús, los nébomes estaban clasificados como hablantes de lengua tepehuana en las anuas de 1616 y 1618. Para la década de los treinta se hacía ya una distinción entre los grupos de nébomes y los ures, ambos referidos como naciones en las crónicas. Sauer encuentra que el padre Tomás Basilio, en 1636, incluía ya en esta clasificación a los yécoras, ubicados en la frontera montañosa entre Chihuahua y Sonora (1998 [1934]:141).

Mientras que los pimas altos que se fueron concentrando en las riberas de los ríos que bañan el desierto de Arizona; los pimas bajos que originalmente vivían en los valles del sur de Sonora -con la excepción de los yécoras asentados en la sierra- terminaron desplazándose hacia los climas más templados y fríos de las tierras altas de la sierra. Esto amplió la distancia entre los pimas bajos y los pimas altos. A pesar de que se mantuviera la contigüidad de estas dos regiones, los procesos históricos y demográficos llevaron a que se presentara una marcada discontinuidad entre su población que ya no solo habitaba en contextos ecológicos distintos sino también distantes.

Sauer había enfatizado el hecho de que la división entre las dos pimerías era de «índole geográfica, no lingǘstica» (1998 [1934]). Tal vez con esto quería subrayar el hecho de que hubiera elementos compartidos entre ellos a pesar de las marcadas diferencias de los medios ecológicos en los que se desenvolvían. La mayoría de las crónicas o recuentos históricos sobre las Pimerías se hicieron en función de la Alta, de tal suerte que los pimas bajos fueron definidos por contraste con los grupos que ya habían sido claramente identificados y estudiados. Podría pensarse entonces que lo que no está visiblemente definido, lo que no representa una totalidad, es lo que corresponde a los pimas, más aún, a los pimas bajos: los que no son. Cuando se habla de los pimas serranos o «montañeses» como se refiere a ellos Carl Sauer, se advierte que presentan un contraste con aquellos que se ubicaban en los valles y tierras bajas de Sonora. Uno de los elementos que se destacan en las crónicas sobre estos grupos es su cercanía con los tarahumaras (SAUER, 1998 [1934]:143). El amplísimo territorio que alguna vez habitaron los grupos a los que se denominó pimas en México, se fue reduciendo dramáticamente hasta quedar circunscrito a una serie de localidades en la región serrana de la frontera entre Sonora y Chihuahua. Una región bastante más pequeña que aquella a la que en el siglo XVII se lo conoció como Pimería Baja. Para Carl Sauer, quién escribía su trabajo sobre los grupos del noroeste de México a mediados de la década de los treinta de siglo pasado, la situación era preocupante, puesto que veía a los pimas bajos en un «acelerado proceso de extinción». En aquel momento, el arqueogeógrafo estadounidense que había puesto tanto empeño en dilucidar la configuración étnica del noroeste de México a la llegada de los españoles, advertía que «Maicoba» era el único poblado «esencialmente pima» que quedaba en esta región (SAUER, 1998[1934]: 144).

\section{Memorias de lugares: los pimas contemporáneos}

Las porciones correspondientes a las Pimerías son ahora habitadas en su mayoría por una población mestiza entre quienes los pimas ocupan pequeños reductos de lo que antes fue su inmenso territorio. Si entendemos 
las Pimerías como el lugar que habitan los pimas, la Pimería Baja está entonces reducida a unos cuantos municipios entre los estados de Sonora y Chihuahua que corresponde a menos de la mitad de la extensión que históricamente fue denominada con este nombre. Por otro lado, los pimas son un pueblo indígena cuyos rasgos particulares son difíciles de percibir a simple vista: no portan un traje tradicional, hay muy pocos hablantes de la lengua y sus formas de vida se asemejan a las de cualquier habitante de estos poblados serranos. Son lo que en la antropología de mediados del siglo XX se consideraba un grupo «aculturado».

Como lo advertía Sahlins en su célebre ensayo «Adiós a los Tristes Trópicos: Etnografía en el contexto de la Historia mundial moderna» ${ }^{3}$, los grupos que fueron etiquetados como «aculturados» (en las décadas de 1930 y 1940) fueron descuidados por los etnógrafos - tal vez su falta de exotismo los hacía poco atractivos. Sin embargo, en contra de la ausencia de interés antropológico, estos pueblos asumieron la responsabilidad de su cultura y aún en el cambio mantuvieron su propia autenticidad (SAHLINS, 1993).

He desarrollado investigación etnográfica con los pimas de la Sierra Madre Occidental por casi quince años, principalmente describiendo y analizando el ritual de Semana Santa en Maycoba y las relaciones entre los pimas y los mestizos. Desde que inicié mi trabajo con los pimas de México me intrigó la relación entre estos y sus homónimos estadounidenses. Cada vez que podía les preguntaba a los pimas de Maycoba y Yepachi sobre su contacto con los pimas de Arizona. Ellos me contaban que gracias a las gestiones del Padre David ${ }^{4}$ se habían organizado distintos encuentros entre los O’oba y los Akimel o'otham tanto en Chihuahua como en Arizona. Cuando les preguntaba si podían comunicarse bien con ellos, me comentaban que no tanto porque «los de allá» hablaban en inglés y en pima no se entendían muy bien.

A pesar de mostrar interés y emoción por estos encuentros la relación entre estos dos grupos de pimas se dio en términos de una historia que les fue contada, la de que eran un mismo gran pueblo: «nos dicen que somos los mismos» me comentaban. En su memoria, los pimas habían ocupado estos territorios escarpados de la Sierra Madre Occidental desde que tenían recuerdos, aunque podían incorporar la idea de que, en un pasado muy lejano «todos había bajado de Alaska» y unos se habían quedado «del otro lado».

En 2013, tuve la oportunidad de visitar la Comunidad Indígena Pima del río Gila en el área de Phoenix Arizona, Estados Unidos. Lo primero que hay que señalar es que está claro que las condiciones de vida de los Akimel O'otham son absolutamente distintas a los de los pimas de México: en Arizona, los pimas viven en reservaciones que ahora son denominadas «Comunidades indígenas» en las que ellos tiene la propiedad de la tierra y de los recursos naturales dentro de ellas; además tienen casinos que son una importante fuente de ingresos que son repartidos entre todos los miembros de la comunidad para garantizar sus condiciones materiales.

Su apariencia física es distinta de la de los pimas en México. Su lengua es la misma, pero existe una variante dialectal importante que dificulta el entendimiento entre los pocos hablantes que quedan de ambos lados de la frontera (mucho más escasos en territorio norteamericano). Por momentos se puede pensar que la única similitud está en la denominación que recibieron de los colonizadores y que asumen como distintivo: «los pimas», es decir, los habitantes de las Pimerías. En el Huhugam Heritage Center ${ }^{5}$ (Museo comunitario de los Akimel O’odham) conocí al presidente de la Delegación Internacional Pima, que está a cargo de establecer el

\footnotetext{
${ }^{3}$ El texto revisado está en inglés y el título original es «Goodbye to Tristes Tropes: Ethnography in the Context of Modern World History» publicado por el Journal of Modern History, University of Chicago, No. 65, March 1993, pp. 1-25.

${ }^{4}$ Fraile capuchino que llegó a esta región en 1990 para llevar a cabo las tareas de catequesis y pastoral indígena en Sonora, mostrando un enorme interés en la preservación de la lengua y la cultura pima.

${ }^{5} \mathrm{El}$ término «Huhugam» se refiere a los «ancestros» en lengua pima de los Akimel O’otham. El nombre de este centro comunitario se traduce como «Centro de herencia ancestral».
} 
contacto y de «fortalecer los lazos» entre los pimas de Arizona y los pimas de Chihuahua y Sonara en México. En esa primera ocasión (hemos mantenido una comunicación constante desde entonces) pude platicar con él sobre sus viajes a México y las comunidades de la Sierra que conocía; narró sus visitas a las comunidades pimas mexicanas en las que conoció a algunos antropólogos de Sonora, al Padre David y también a algunas personas que trabajan en instituciones culturales o de asuntos indígenas en Chihuahua; además de que tenía una relación cercana con varios pimas, entre ellos Don Alberto Vargas Castellanos, Gobernador Supremo de la Tribu Pima de Chihuahua. A diferencia de lo que nos habían comentado los pimas de Yepachi, el presidente de la Delegación Internacional Pima (de ahora en adelante PDIP) señaló que sí se comunicaba con ellos en su lengua y que se podían entender muy bien, sobre todo desde que él se familiarizó un poco con el español y eso le permitió entender mejor a los pimas que viven en México.

En aquella primera conversación, el PDIP señaló que todos los indígenas de Sonora y Chihuahua eran pimas: los pápagos, los guarijíos, los yaquis, etc. Incluso dijo que él los entendía a todos, pero que los pimas de Yepachi y Madera eran como sus antepasados; en ese momento no entendía semejante aseveración, sin embargo, después de la revisión histórica se puede concluir que: si los pimas son los habitantes de las pimerías, estos grupos efectivamente entrarían dentro de esa clasificación puesto que son los habitantes de la Baja Pimería histórica. En contraste, me llamó la atención que no señalara su cercanía con los Tohon O’otham que son sus vecinos. De hecho, desde la etnografía norteamericana, estos grupos son pensados como dos variantes de pimas: los del río y los del desierto (UNDERHILL, 1979 [1941]). Comparten la lengua (con variantes dialectales), algunas fiestas y además tienen la misma nacionalidad.

En los discursos de ambos lados de la frontera podemos ver que los grupos le atribuyen un vínculo más cercano con el pasado a los pimas que se quedaron «del otro lado». Los pimas que habitan la región Serrana del noroeste de México se refieren a los de Arizona como «los que se quedaron allá», aludiendo a un viaje que inició en el norte y fue avanzando hacia al sur (tal como lo suponen los estudios sobre los procesos de distribución de la población para esta región). Pero los pimas del desierto del suroeste norteamericano piensan a los pimas de México como los que todavía viven como antes, los que son como ellos eran.

Entre los pimas mexicanos encontramos diferencias que nos permiten identificarlos en tres grupos: Los pimas de Maycoba establecidos en territorio sonorense en las inmediaciones del actual municipio de Yécora; En Chihuahua, los pimas de Yepachi que están asentados en el municipio de Temósachic y los pimas de Madera que habitan desde mediados del siglo XX en distintas localidades de esa zona. Cada uno de estos grupos tiene condiciones históricas y sociales distintas que han jugado un papel relevante en la forma en que se piensan así mismos y se visualizan como parte de una unidad cultural.

Los pimas de Maycoba, como lo han señalado diversos autores (SAUER, 1998[1934];OSEGUERA, 2013), son considerados como el último reducto de la costumbre de este pueblo indígena. Este grupo aglutina a todos los pimas que viven en el estado de Sonora en las distintas rancherías del municipio de Yécora y que se congregan en el pueblo de Maycoba que funge como su centro político y ceremonial. Este es el grupo que tiene el mayor número de hablantes de lengua pima. Sus relaciones cotidianas de conflicto y cooperación con los mestizos con los que cohabitan han jugado un papel relevante en la demarcación de fronteras étnicas que se han traducido en la persistencia de su costumbre (OSEGUERA, 2013; HOPE, 2016). Esto se puede ver de manera clara en la tradicional celebración de la Semana Santa, en donde los pimas se erigen como el grupo en el poder (los fariseos) que somete a los mestizos (los judíos) a partir de una lucha cósmica expresada en este 
ritual que invierte los términos de las relaciones entre estos dos en un performance que demarca el espacio pima a partir de una serie de procesiones que concluyen con luchas para vencer al mal y regresar al orden.

A unos 40 kilómetros de Maycoba, pero ya en el estado de Chihuahua, se encuentra el poblado de Yepachi, un importante asentamiento de población pima que guarda cierta cercanía y parentesco con los pimas de Sonora; sin embargo, la separación geopolítica ha terminado por hacer mella en las relaciones de estos grupos que presentan una discontinuidad en términos de sus condiciones de vida, su ritualidad y las relaciones con otros grupos. Los pimas de Yepachi (que incluyen a los pobladores de las distintas rancherías satelitales a esta localidad) enfrentan una dramática pérdida de su lengua. Sin embargo, mantienen la celebración de un ritual agrícola muy relevante para esta cultura: el yúmare. Este rito propiciatorio de buenas cosechas y saludse celebra durante tres noches en el otoño o en el invierno en las que las mujeres danzan y los músicos reproducen los cantos de sus ancestros para dar continuidad a los o'oba en el tiempo.

A varios kilómetros de ahí, hacia el norte del estado de Chihuahua, encontramos a los pimas de Madera distribuidos en distintas pequeñas localidades internadas en la escarpada sierra de esta región e incluso en la cabecera municipal en donde tienen un asentamiento importante. La presencia de los pimas en este municipio es históricamente reciente (producto de la migración desde Yepachi mediados del siglo XX); sin embargo, en la memoria de quienes se identifican como o’oba, ellos han estado aquí «desde siempre». En una entrevista realizada en 2015, la gobernadora nos decía que había población pima «criolla» en esta región y por eso cuando llegaron los pimas procedentes de Yepachi fueron bien recibidos; incluso señalaba que sufrieron la invasión de los apaches, pero con astucia lograron vencerlos y hasta se mezclaron con ellos. Ahora algunos pimas de Madera dicen «nosotros somos pimas apaches».

El apache, como lo veíamos desde las crónicas de los misioneros jesuitas, representa la «otredad»;aquel que es opuesto a todo lo «civilizado», el salvaje aguerrido e incluso sanguinario al que se tenía que combatir por todos los medios. El vencimiento o la integración de los apaches es visto desde las crónicas coloniales hasta los relatos actuales como un proceso civilizatorio. Los misioneros jesuitas evaluaban el nivel de desarrollo de un grupo en función de su lejanía o cercanía con los modos de vida apaches. Así, los nómadas recolectores y cazadores se asemejaban más a los apaches (como el caso de los pápagos descritos en las crónicas del siglo XVII), mientras que aquellos que habían logrado una vida más sedentaria eran considerados más avanzados.

En los relatos pimas -tanto este que citamos aquí como algunas glosas que hemos escuchado entre los pimas de Yepachi y de Maycoba- los apaches eran un enemigo a vencer, pero no a desaparecer (como lo perseguían las políticas coloniales). Es la representación de una alteridad que ratifica la condición de la cultura pima. Su presencia en la memoria de estos grupos es fundamental en la construcción de su identidad étnica. Los apaches se vencieron a partir de su desplazamiento hacia el norte o su domesticación y fusión con los grupos con los que se encontraban.

Algunos pimas de Maycoba, cuándo les preguntamos sobre los pimas de Arizona, nos dicen «esos son apaches», es decir, los que se fueron más al norte. Aunque creen que comparten con ellos ciertos elementos culturales, se distinguen con mucha claridad. Don Alberto, de Yepachi, nos dice que «allá en Arizona hay algunos pimas y algunos apaches» y con esto muestra su conocimiento de primera mano puesto que ha estado allá y ha convivido con ellos; en la visión de Don Alberto los apaches son los Maricopa. Por su parte,los pimas gileños no sólo se distinguen de manera categórica de los apaches, sino que se distancian de ellos pues en sus enfrentamientos perdieron a muchos de sus integrantes. 


\section{Los usos de la memoria: A manera de conclusión}

Las pimerías y sus habitantes han sufrido profundas transformaciones a lo largo del tiempo, como hemos tratado de mostrar en este texto. Los pimas de Arizona, habitantes contemporáneos de la Pimería Alta, se aproximaron a la Pimería Baja en busca de sí mismos; de lo que son en el reflejo de aquellos que, desde su punto de vista, siguen siendo lo que ellos una vez fueron. Sin embargo, de los tres grupos de pimas que habitan en el septentrión mexicano, los Akimel O’otham han generado un vínculo más estrecho con los «pimas apaches» de Madera. Esta cercanía construida nos habla de un proceso de selección de identidades en el que se reconoce entre los grupos aquellas similitudes o aspectos compartidos que armonicen mejor con el discurso que se han elaborado sobre sí mismos.

Resulta un tanto paradójico que los pimas de Madera encuentren una continuidad con los de Arizona, mientras que fragmentan su relación con los pimas de Maycoba a quienes piensan como un grupo más lejano con el que tienen una interacción mínima e incluso dificultades para comunicarse en su lengua (en Madera hay apenas un par de hablantes de pima). Por otro lado, los pimas de Yepachi son vistos como "pimas raramurizados» ${ }^{6}$ por su relación más cercana con otros pueblos indígenas de Chihuahua. Mientras tanto, la percepción sobre los pimas de Madera es que han perdido la costumbre.

Tanto entre los pimas de Arizona como con los de Madera, las danzas tradicionales se han apartado de sus contextos rituales para presentarse frente al otro como una credencial de la «indianidad» de un grupo que en la vida cotidiana se ha desdibujado como distinto pero que reaparece en los festivales y encuentros culturales. Esta sensación de comodidad que expresan los grupos sobre sus interacciones puede obedecer también a la ausencia de una competencia étnica que hace innecesario mostrar que se sigue siendo pima, basta con que ellos así lo afirmen.

La provocadora propuesta de Sahlins de mirar a los pueblos que han sido etiquetados como «aculturados» a partir de una etnografía histórica para dar cuenta de las transformaciones estructurales de la cultura, fue la vía que desveló como -ante las omisiones etnográficas, las negaciones históricas y la invisibilización ante la llamada sociedad nacional mexicana- los pimas han tomado las riendas de su cultura a partir de una narrativa del pasado propia; una memoria que los invita a imaginar un futuro en el que siguen siendo pimas.

\section{REFERENCIAS BIBLIOGRÁFICAS}

BRANIFF CORNeJO, B. (1992). La Frontera Protohistórica Pima-Ópata en Sonora, México. Tomo I. México: Instituto Nacional de Antropología e Historia.

GONZÁLEZ, RODRÍGUEZ, L. (1977). Etnología y Misión en la Pimería Alta. México:Universidad Nacional Autónoma de México.

HOPE, M. (2006). Pimas. México: Comisión Nacional para el Desarrollo de los Pueblos Indígenas.

HOPE, M. (2016). Las Pimerías. Hacia un campo de estudio etnológico en el noroeste de México, Tesis de doctorado. España: Universidad de Salamanca.

JIMÉNEZ NÚÑEZ, A. (2003). «Historia y antropología: Las fronteras de América del Norte», Revista Española de Antropología Americana. Madrid, n. ${ }^{\circ} 33:$ 9-113.

OSEGUERA, A. (2013). La persistencia de la costumbre pima. Interpretaciones desde la antropología cognitiva. México: Universidad Autónoma Metropolitana-Instituto Nacional de Antropología e Historia/Juan Pablo Editores.

${ }^{6}$ Aluden con esto a su cercanía con los rarámuri (o tarahumaras), el pueblo indígena más numeroso que habita en la Sierra Tarahumara. 
ORTIZ, A. (1983). Southwest (Vol. 10). Washington Smithsonian Institution.

SAHLINS, M. (1993). «Goodbye to Tristes Tropes: Ethnography in the Context of Modern World History», Journal of Modern History. University of Chicago, n. ${ }^{\circ}$ 65:1-25.

SAUER, C. (1998 [1934]). «La distribución de las tribus y las lenguas aborígenes del noroeste de México» Aztatlán. México: Siglo XXI Editores, pp. 97-199.

UNDERHILL, R. (1941). The Papago and Pima Indians of Arizona. Colorado:The Filter Press. 